GfÖ Ecological Society of Germany,

Austria and Switzerland

Basic and Applied Ecology 11 (2010) 35-44

\section{Basic and \\ Applied Ecology}

www.elsevier.de/baae

\title{
Patterns and mechanisms responsible for the relationship between the diversity of litter macro-invertebrates and leaf degradation
}

\author{
Mickaël Hedde*, Fabrice Bureau, Matthieu Chauvat, Thibaud Decaëns \\ Laboratoire d'Ecologie, UPRES-EA 1293 ECODIV, Fédération de Recherche SCALE, Université de Rouen, F-76821 Mont Saint \\ Aignan Cedex, France
}

Received 11 August 2008; accepted 23 October 2009

\begin{abstract}
Laboratory microcosms were used to determine how leaf degradation processes $\left(\mathrm{C}-\mathrm{CO}_{2}\right.$ release and leaf mass loss) are affected by the diversity of soil macro-invertebrate assemblages (comprising earthworms, woodlice and millipedes). The relationships were tested using different measures of diversity (number of species and trait dissimilarities). Net diversity effects and transgressive overyielding were calculated to disentangle the relative impacts of negative, neutral and positive species interactions on the relationships observed.

Minimum trait dissimilarities were found to be correlated with leaf mass loss and, to a lesser extent, with $\mathrm{C}-\mathrm{CO}_{2}$ release. This suggests that process rates increase as trait similarity in species assemblage decreases. Conversely, increasing the number of species resulted in the saturation of process rates after 1-2 species had been added to a microcosm. The process rates observed could mainly be explained by positive species interactions $(40-50 \%$ of microcosms being process-dependent), followed by neutral interactions (20-40\%) and selection effects or negative interactions (less than 20\%). These results thus suggest that the effects of a soil macro-invertebrate assemblage on soil processes are more likely to be driven by complementarity or facilitation than by competition.
\end{abstract}

(c) 2009 Gesellschaft für Ökologie. Published by Elsevier Gmbh. All rights reserved.

\section{Zusammenfassung}

Es wurden Labormikrokosmen benutzt, um zu bestimmen, wie die Blattzersetzungsprozesse (C CO2-Freisetzung und Blattmassenverlust) durch die Diversität der Boden-Makroinvertebraten-Gemeinschaften (zusammengesetzt aus Würmern, Asseln und Tausendfüsslern) beeinflusst werden. Die Beziehungen wurden untersucht, indem verschiedene Maße der Diversität (Artenzahl und Dissimilarität der Eigenschaften) benutzt wurden. Die Netto-Diversitätseffekte und der transitive Überfluss wurden berechnet, um die relativen Auswirkungen der negativen, neutralen und positiven Interaktionen zwischen den Arten auf die beobachteten Beziehungen zu trennen. Die Dissimilarität sowohl in den Eigenschaften der Faezes als auch in den morphologischen Eigenschaften korrelierten mit dem Verlust der Blattmasse und in geringerem Maße mit der C CO2-Freisetzung und lässt vermuten, dass eine begrenzte Ähnlichkeit zwischen den koexistierenden Arten zu einer höheren Rate des Prozesses führt. Eine Erhöhung der Artenzahl resultierte in einer Sättigung des Prozesses wenn 1-2 Arten zu den Mikrokosmen hinzugefügt wurden. Die beobachteten Raten der Prozesse konnten vor allem mit positiven Interaktionen zwischen den Arten erklärt werden $(40 \%$ bis $50 \%$ der Mikrokosmen waren prozessabhängig), gefolgt von neutralen Interaktionen (20\% bis $40 \%)$ und Selektionseffekten

\footnotetext{
${ }^{*}$ Corresponding author. Present address: INRA, UR 251 PESSAC, F-78000 Versailles, France. Tel.: +33 130833270 ; fax: +3313083 3259 .

E-mail address: mhedde@versailles.inra.fr (M. Hedde)
} 
bzw. negativen Interaktionen (weniger als 20\%). Die Ergebnisse lassen daher vermuten, dass die Auswirkungen einer Boden-Makroinvertebraten-Gesellschaft mit größerer Wahrscheinlichkeit durch Komplementarität oder Begünstigung als durch Konkurrenz gesteuert werden.

(c) 2009 Gesellschaft für Ökologie. Published by Elsevier Gmbh. All rights reserved.

Keywords: Litter degradation; Biodiversity-function relationship; Functional diversity; Morphological diversity; Species richness

\section{Introduction}

The effects of biodiversity on ecosystem processes have been the focus of numerous studies in the literature in recent decades. The new challenge is not to determine whether, but how, biodiversity matters, i.e. which mechanisms are responsible for diversity-process patterns (Loreau et al. 2001b; Rosenfeld 2002; Naeem \& Wright 2003; Hooper et al. 2005). To date, this topic has mainly been explored in the context of plant diversity and grassland productivity relationships, so that any generalizations to other taxonomic groups or ecosystems being difficult. For instance, despite the recognized impact of soil fauna on soil functioning (Lavelle et al. 2006), the relationships between soil animal diversity and the rate of below-ground processes remains obscure (Huhta, Persson, \& Setälä 1998). In forest soils, macroinvertebrates can have a tremendous impact on organic matter decomposition through the processing of large quantities of litter (Cárcamo, Abe, Prescott, Holl, \& Chanway 2000; Hedde, Bureau, Akpa-Vinceslas, Aubert, \& Decaëns 2007b) and the regulation of microbial communities (Lavelle \& Spain 2001).

A first step necessary to explore the relationship between macro-invertebrate diversity and soil processes is the identification of relevant biodiversity measures to estimate species assemblage effect(s) on a given function. Species number has been widely used in the past, but it is now considered that it may not be a satisfactory surrogate for biodiversity in this context (Diaz \& Cabido 2001). Conversely, the use of trait-based approaches may generate more reliable results in many cases (Diaz \& Cabido 2001Lavorel \& Garnier 2001). Numerous studies on plant ecology have focused on physiological and morphological traits such as specific leaf area, seed size or number (Pywell et al. 2003; Díaz et al. 2004). Heemsbergen et al. (2004) more recently explained the effects of soil macrofauna diversity on soil processes in terms of interspecific functional dissimilarity. They applied the species functional role to litter mass loss, litter fragmentation, gross nitrate productivity and soil respiration under a trait-based approach. To limit inconsistencies in use of the trait concept, references in this paper are made to the terminology proposed by Violle et al. (2007). Traits thus refer to any morphological, physiological or phenological feature measurable at the individual level, from the cell to the whole-organism level, without reference to the environ- ment or any other level of organization. Effect traits correspond to any trait which reflects the effects of an organism on ecosystem properties.

Furthermore, it remains necessary to clearly understand the relative importance of species interaction mechanisms in soil biodiversity-function relationships. Despite the predicted role of competitive exclusion in determining local biota assemblage, a huge variety of life forms inhabits just a few handfuls of soil, thus constituting the 'enigma of soil biodiversity' (Anderson 1975; Wardle 2006). Positive and neutral interactions are therefore more likely to develop between organisms because a very low intensity of species competition and important niche partitioning are suspected to explain this enigma. Niche complementarity and facilitation are two primary mechanisms that may account for positive patterns through greater efficiency in resource use (Loreau et al. 2001b). Alternatively, patterns may result from a sampling effect, i.e. an increased probability of selecting species with extreme functional traits at higher levels of species richness (Loreau 2000a). Conversely, process rates may be mitigated by competition within the assemblage. The relative importance of these mechanisms deserves greater attention (Hooper et al. 2005).

In the present study, an experimental approach was used to test the hypothesis that beech leaf degradation can be related to the diversity of soil macro-invertebrates within one feeding group. Two specific questions were tested. First, we tested whether trait-based approaches provided clearer insight into diversity-process relationships than species richness. For this, morphological traitand effect trait-based approaches were employed to build morphological and functional diversity gradients. Second, efforts were made to identify the mechanisms implicated in the patterns observed, in order to test whether positive or neutral interactions are more important than competition when trying to explain how soil faunal diversity affects process rates.

\section{Materials and methods}

\section{Experimental design}

Microcosms were set up with leaf litter and saprophageous macro-invertebrates collected in the Eawy beech forest, Normandy, France (Aubert et al. 2003). The set of species used in this work was selected according to 
three criteria. First, species were abundant in the field (Hedde, Aubert, Bureau, Margerie, \& Decaëns 2007a). Second, species exhibited different abilities on litter degradation (Hedde et al. 2007b). Finally, species had different morphological features. Four invertebrate species were thus used: the woodlouse Oniscus asellus Linnaeus 1758, the earthworm Dendrodrilus rubidus (Savigny, 1826) and the millipedes Glomeris marginata (Villiers, 1789) and Cylindroiulus latestriatus (Curtis, 1844). Invertebrates were maintained under experimental conditions for at least one week before the start of the experiment to acclimatize them and prevent the input of non-experimental material.

Beech leaves were collected from a pure 120-year-old stand (see stand characteristics in Aubert et al. 2003). Preliminary experiments had demonstrated high invertebrate mortality (more than 60\%) on fresh leaves. Conversely, animals placed on partially decayed leaves had a satisfactory survival rate (85\%) (Hedde et al. 2007b). Since it proved impossible to rear macro-invertebrates on fresh beech litter, partially decayed leaves were used in the experiments. Litter was collected in March 2004 and partially decayed beech leaves of similar size and decomposition stage (judged by color and texture) were separated from bulk material in the laboratory. The leaves were gently washed to remove non-leaf material (invertebrate faeces, bud scales, etc.), oven-dried $\left(40{ }^{\circ} \mathrm{C}\right)$ for 3 days, homogenized and stored in plastic boxes. On average, partially decayed leaves contained $416.9( \pm 11.9) \mathrm{mgC} \mathrm{g}^{-1} \mathrm{DW}, 18.5$ $( \pm 0.3) \mathrm{mgN} \mathrm{g}^{-1} \mathrm{DW}$ and had a $\mathrm{C} / \mathrm{N}$ ratio of $22.6( \pm 0.7)$. These contents have been measured with gas chromatography with a CHN pyrolysis micro-analyzer (NA 2000, Thermofisher, formerly Carlo Erba).

Hermetic, dietary glass jars $(200 \mathrm{ml}, 8-\mathrm{cm}$ high and $7-\mathrm{cm}$ in diameter) were used as microcosms. The beech leaves were soaked in deionized water to achieve the water content prevailing in the field (about $60 \%$ of dry weight). Invertebrates were then introduced to test for all possible mixtures from one to four species. Care was taken to use similarly sized animals of each species in the experiments. The coefficient of variation of body mass ranged from $5 \%$ to $10 \%$ in $C$. latestriatus and D. rubidus, respectively. Because species abundance influences the net diversity effects (Polley, Wilsey, \& Tischler 2007), we chose to fix both the number of individuals per species and the density of individuals per unit of litter mass. Thus, in mono-specific microcosms, one individual per species was placed with $0.30 \mathrm{~g}$ of litter. Further, in 2-, 3- and 4-species microcosms, one individual per species were added to $0.60,0.90$ and $1.20 \mathrm{~g}$ of litter, respectively, thus maintaining a density of one individual per $0.30 \mathrm{~g}$ of litter. Controls containing litter without invertebrates were set up in the same way. Empty jars were also used to take account of initial atmospheric $\mathrm{C}-\mathrm{CO}_{2}$. Three replicates were built for each treatment. The microcosms were stored for 3 weeks in climate chambers $\left(10 \pm 1{ }^{\circ} \mathrm{C} ; 11: 13 \mathrm{~h}\right.$ LD photoperiod).

\section{Leaf degradation measurements}

Leaf mass loss was calculated as the difference between the initial leaf dry mass and the dry mass of leaf remnants at the end of incubation periods. A $20 \mathrm{ml}$ flask filled with $\mathrm{NaOH}(0.2 \mathrm{M})$ was placed in each microcosm to assess carbon mineralization $\left(C_{\min }\right)$. $\mathrm{C}-\mathrm{CO}_{2}$ release (invertebrate respiration+microbial C mineralization) was calculated by comparing initial and final soda conductivity for determined incubation periods (Heemsbergen et al. 2004):

$C_{\min _{i-j}}=\left(\left(S c_{i}-S c_{j}\right)-\left(S c_{i \text { atm }}\right.\right.$ and $\left.\left.S c_{j \mathrm{~atm}}\right)\right) k$

where $C_{\min _{i-j}}$ is the amount of $\mathrm{C}-\mathrm{CO}_{2}$ released $(\mathrm{mg})$ between $i$ and $j$ incubation days, $S c_{i}$ and $S c_{j}$ are the $\mathrm{NaOH}$ conductivities measured after $i$ and $j$ incubation days $\left(\mathrm{mS} \mathrm{cm}^{-1}\right), S c_{i \text { atm }}$ and $S c_{j \text { atm }}$ are the $\mathrm{NaOH}$ conductivities in empty microcosms after $i$ and $j$ incubation days $\left(\mathrm{mS} \mathrm{cm}^{-1}\right)$, and $k$ is a constant determined by standard curves $\left(\mathrm{mg} \mathrm{C} \mathrm{mS}^{-1} \mathrm{~cm}\right)$. Carbon mineralization was expressed as cumulative $\mathrm{C}-\mathrm{CO}_{2}$ release after 22 days of incubation

\section{Indices of assemblage diversity}

To test whether morphological traits or faeces properties could be used to explain soil biodiversityprocess relationships, a trait-based approach was adopted that allowed the building of morphological and functional diversity gradients.

Effect traits that had been shown to reflect invertebrate leaf degradation abilities (Hedde et al. 2007b) through the characteristics of their faeces, i.e. defaecation rate, Corg content, $\mathrm{C} / \mathrm{N}$ ratio and mean weighted size of organic debris in faeces (Table 1) were selected and used. To prevent any tautological interpretation of the results, neither leaf mass loss nor $\mathrm{C}$ mineralization was included in the faeces properties matrix. Faeces were collected at the end of the experiment, oven-dried at $40{ }^{\circ} \mathrm{C}$ and weighed to calculate daily defaecation rate. Faeces organic carbon and total nitrogen contents were then estimated by gas chromatography with a $\mathrm{CHN}$ pyrolysis microanalyzer. They were finally segregated into four particle size classes by dry sieving $(2-1,1-0.5,0.5-0.2$ and $0.2-0.1 \mathrm{~mm}$ ). Each particle size class was weighed to calculate the mean weighted size of particle in faeces:

$$
M W P S=\frac{\left(1.5 \times M_{[2-1 \mathrm{~mm}]}+0.75 \times M_{[1-0.5 \mathrm{~mm}]}+0.35 \times M_{[0.5-0.2 \mathrm{~mm}]}+0.15 \times M_{[0.2-0.1 \mathrm{~mm}]}\right)}{100}
$$


Table 1. Mean (SE) of faeces features used as effect traits of invertebrate species on beech leaf degradation.

\begin{tabular}{llllr}
\hline & Faeces Corg $\left(\mathrm{mg} \mathrm{g}^{-1}\right)$ & Faeces C/N ratio & Defaecation $\left(\mathrm{mg} \mathrm{d}^{-1}\right)$ & $\mathrm{MWPS}(\mu \mathrm{m})$ \\
\hline Cylindroiulus latestriatus & $43.6(0.2)$ & $24.0(0.4)$ & $2.0(0.5)$ & $897(38)$ \\
Dendrodrilus rubidus & $39.9(0.4)$ & $19.7(0.3)$ & $0.7(0.2)$ & $389(11)$ \\
Glomeris marginata & $44.0(0.1)$ & $24.0(0.1)$ & $1.1(0.4)$ & $1083(99)$ \\
Oniscus asellus & $41.6(0.4)$ & $22.2(0.1)$ & $0.4(0.2)$ & $680(28)$ \\
\hline
\end{tabular}

Mean weighted particle size (MWPS) refers to the ability to fragment leaves, the less the MWPS is, the more the leaves are fragmented.

Table 2. Categorized morphological traits of invertebrate species.

\begin{tabular}{lllll}
\hline & Body length $(\mathrm{mm})$ & Body width $(\mathrm{mm})$ & Biomass $(\mathrm{mg})$ & Comminution structure \\
\hline Cylindroiulus latestriatus & $>20$ & $1-2$ & $<100$ & Mandible \\
Dendrodrilus rubidus & $>20$ & $>5$ & $>100$ & Gizzard \\
Glomeris marginata & $<20$ & $>5$ & $>100$ & Mandible \\
Oniscus asellus & $<20$ & $3-4$ & $<100$ & Mandible \\
\hline
\end{tabular}

where $M_{[x-y \mathrm{~mm}]}$ is the mass of the particle size class $x-y$ $\mathrm{mm}$. Factors correspond to the means of particle size classes (in $\mathrm{mm}$ ).

Morphological traits were chosen from attributes assumed to be related to resource foraging and litter fragmentation, i.e. body length, width or diameter, weight and comminution apparatus (the anatomical structure that grinds leaf material). Body measures reflected individual abilities to penetrate into the litter, with the assumption that, for instance, small and long individuals were able to penetrate more easily into the litter and thus access additional resources that were not available to more compact animals. The comminution apparatus reflected how invertebrates physically modify litter. Traits were categorized to generate a qualitative matrix (Table 2), on which a multiple correspondence analysis (MCA) was performed (Tenenhaus \& Young 1985). This provided a trait space defined by the dimensions of the species cloud in the factorial space.

Trait dissimilarities were calculated using species factorial scores on MCA axes by computing the minimum and the mean nearest-neighbour Euclidean distances (Weiher, Clarke, \& Keddy 1998; Stubbs \& Bastow Wilson 2004). The minimum nearest-neighbour distance (minNND) measures the absolute limit of trait similarity among species. If a process rate varies with the assemblage minNND, this indicates that only interactions between the two 'closer' species drive the total assemblage effect. On the other hand, the mean nearestneighbour distance (mNND) indicates how tightly packed the species are: the smaller the mNND, the more closely packed the species are, according to effect or morphological traits. Then, if a process rate varies with the assemblage $\mathrm{mNND}$, this indicates that interactions between all species drive the assemblage effect.

\section{Net diversity effects and overyielding}

After subtracting the value of invertebrate-free treatment, single-species effects on leaf mass loss and $\mathrm{C}-\mathrm{CO}_{2}$ release were calculated from monoculture results and expressed per animal dry mass per day. The expected effect of a given assemblage on processes was estimated as the sum of single-species effects weighted by their relative dry masses in a mixture. This represents the null hypothesis of no interaction effects. The net diversity effect is the difference between the observed and expected effects of the species mixture. Mean net diversity effects were calculated for each level of species number and minimum and mean nearest-neighbour distances. We further estimated transgressive overyielding, named Dmax (Loreau 1998), by calculating for each level of species number, minNND and mNND, the mean deviation from the maximum single-species effect.

Combination of the results obtained for net diversity effect (NDE) and Dmax discriminates four types of mechanisms (see Appendix A):

(1) $\mathrm{NDE}<0$ reveals underyielding and suggests that some species interactions (e.g. competition) act negatively on process rates.

(2) $\mathrm{NDE}=0$ underlines a lack of interactions or a situation where interactions have no effect on processes.

(3) NDE $>0$ and Dmax $<0$ (non-transgressive overyielding) corresponds to a situation where the effect 
of species assemblage is driven by the effect of a highly performing species ( $=$ selection effect; Loreau 2000b).

(4) $\mathrm{NDE}>0$ and Dmax $>0$ (transgressive overyielding) indicates that the positive effect of species assemblage on the amount of processes results from species complementarity or facilitation.

\section{Statistical analyses}

Data were tested for normality and homoscedasticity conditions using Shapiro's and Bartlett's tests, respectively. When both conditions were satisfactory, means were compared using one-way ANOVAs and the Tukey HSD tests. When at least one assumption was violated, non-parametric tests (Kruskal-Wallis $\chi^{2}$ rank sum test and pair-wise Kolmogorov-Smirnov test with Bonferroni correction) were preferred. The effects of diversity on leaf degradation were assessed using linear regression (adjusted $r$ with Bonferroni correction). Differences between zero and (i) net diversity effects or (ii) Dmax, were tested using Student's two-tailed $t$ test. All statistical tests were performed at $\alpha=0.05$ using $\mathrm{R}$ software (R Development Core Team 2004).

\section{Results}

\section{Single-species effects}

The loss of beech leaf mass was significantly greater in mono-specific microcosms than in animal-free microcosms, whatever the species considered (from 1.5 to 3.1-fold higher in the presence of $O$. asellus and C. latestriatus, respectively). Significant differences were observed between species in terms of leaf mass loss, the lowest value being with $O$. asellus $\left(2.3 \mathrm{mg} \mathrm{d}^{-1}\right)$ and the highest with $C$. latestriatus $\left(4.7 \mathrm{mg} \mathrm{d}^{-1}\right)$ (Fig. 1A). No significant single-species effect on $\mathrm{C}-\mathrm{CO}_{2}$ release was observed (Fig. 1B), except in the presence of D. rubidus (values about 2-fold higher).

\section{Species number effects}

Significantly positive values for the net diversity effect and Dmax were recorded for both leaf mass loss and $\mathrm{C}-\mathrm{CO}_{2}$ release in 2-species microcosms (Figs. 2A and B). In 3-species microcosms, net diversity effect values were significantly positive and Dmax did not differ from zero. In 4-species assemblages, the net diversity effect was null on leaf mass loss and significantly negative on $\mathrm{C}-\mathrm{CO}_{2}$ release.
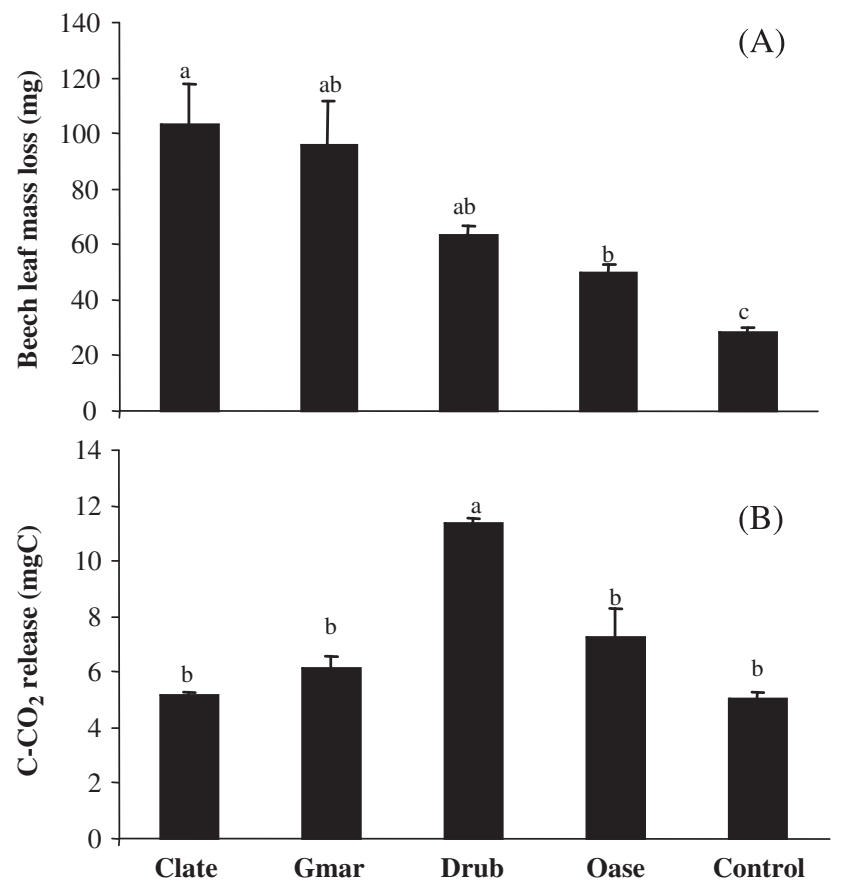

Fig. 1. Mean beech leaf mass loss (A) and $\mathrm{C}-\mathrm{CO}_{2}$ release (B) in single species microcosms after 3 weeks. Bars are standard errors; different letters indicate significant mean differences $(\alpha=0.05)$. Clate $=C$. latestriatus; $\mathrm{Gmar}=G$. marginata, Drub $=D$. rubidus; Oase $=O$. asellus; Control $=$ animal-free microcosms.
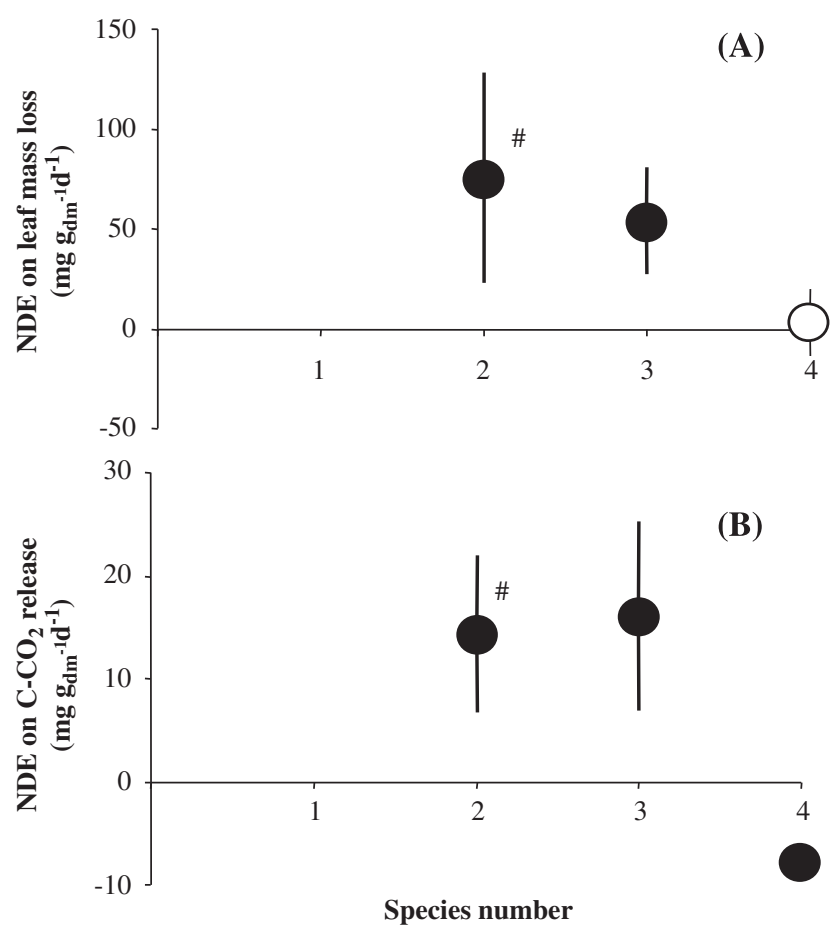

Fig. 2. Net diversity effect of species number in an assemblage on leaf mass loss (A) and $\mathrm{C}-\mathrm{CO}_{2}$ release (B). Bars are standard errors; open symbols $=$ net diversity effects did not differ from zero; solid symbols $=$ under- or over-yielding $(p<0.05)$; $\#=$ transgressive overyielding (significant Dmax at $p<0.05$ ). 


\section{Influence of the dissimilarity of effect traits}

The minNND value in the effect trait space positively and linearly influenced the net diversity effect on leaf mass loss (Fig. 3A). The Dmax value was significantly positive for the two highest levels of dissimilarity (Fig. 3A). No clear pattern could be observed using mNND (Fig. 3B). However, six levels exhibited statistically positive net diversity effects, and four of them presented Dmax values that differed significantly from zero.

Similar results were found regarding the influence of faeces characteristics dissimilarity on $\mathrm{C}-\mathrm{CO}_{2}$ release (Figs. 3C and 3D). The net diversity effect positively increased with increasing minNND (Fig. 3C), and displayed positive Dmax values at three levels. While mNND influenced the net diversity effect on $\mathrm{C}-\mathrm{CO}_{2}$ release $\left(\chi^{2}=21.75, p<0.010\right.$; Fig. $\left.3 \mathrm{C}\right)$, this relationship was not linear. One level had a significantly negative net diversity effect on $\mathrm{C}-\mathrm{CO}_{2}$ release, while seven others exhibited significantly positive values, four of them with positive Dmax values (Fig. 3D).

\section{Influence of dissimilarity of morphological traits}

The net diversity effect on leaf mass loss was positively influenced by minNND in the morphological trait space (Fig. 4A). All levels of minNND exerted a positive net diversity effect, with two of them presenting positive Dmax values (Fig. 4A). The net diversity effect also varied in line with mNND $(F=2.96, p<0.05)$ although no linear correlation was found (Fig. 4B). Six levels exhibited a significantly positive net diversity effect, four of them with positive Dmax values (Fig. 4B).

Net diversity effects on $\mathrm{C}-\mathrm{CO}_{2}$ release did not vary linearly with minNND and $\mathrm{mNND}$ in the morphological trait space. All levels of minNND yielded more C mineralization than expected without interactions, and three of them had significantly positive Dmax values (Fig. 4C). With the exception of two cases $(\mathrm{mNND}=1.68$ and $\mathrm{mNND}=1.76)$, all $\mathrm{mNND}$ levels exhibited significantly positive net diversity effects, and four of them also had positive Dmax values (Fig. 4D).

\section{Correlations between indices}

MinNND values in the effect and morphological trait spaces positively correlated with each other $(r=0.77$, $p<0.001)$. This relationship could only be interpreted in the way that effect trait dissimilarity, which represents a measure of functional diversity, is influenced by morphological trait dissimilarity, which in turn reveals morphological diversity. Dissimilarity indices were negatively correlated with the number of species $(0.37<r<0.56 ; p<0.05)$.

\section{Discussion}

The leaf mass loss rates observed during this study were within the range of values reported by other
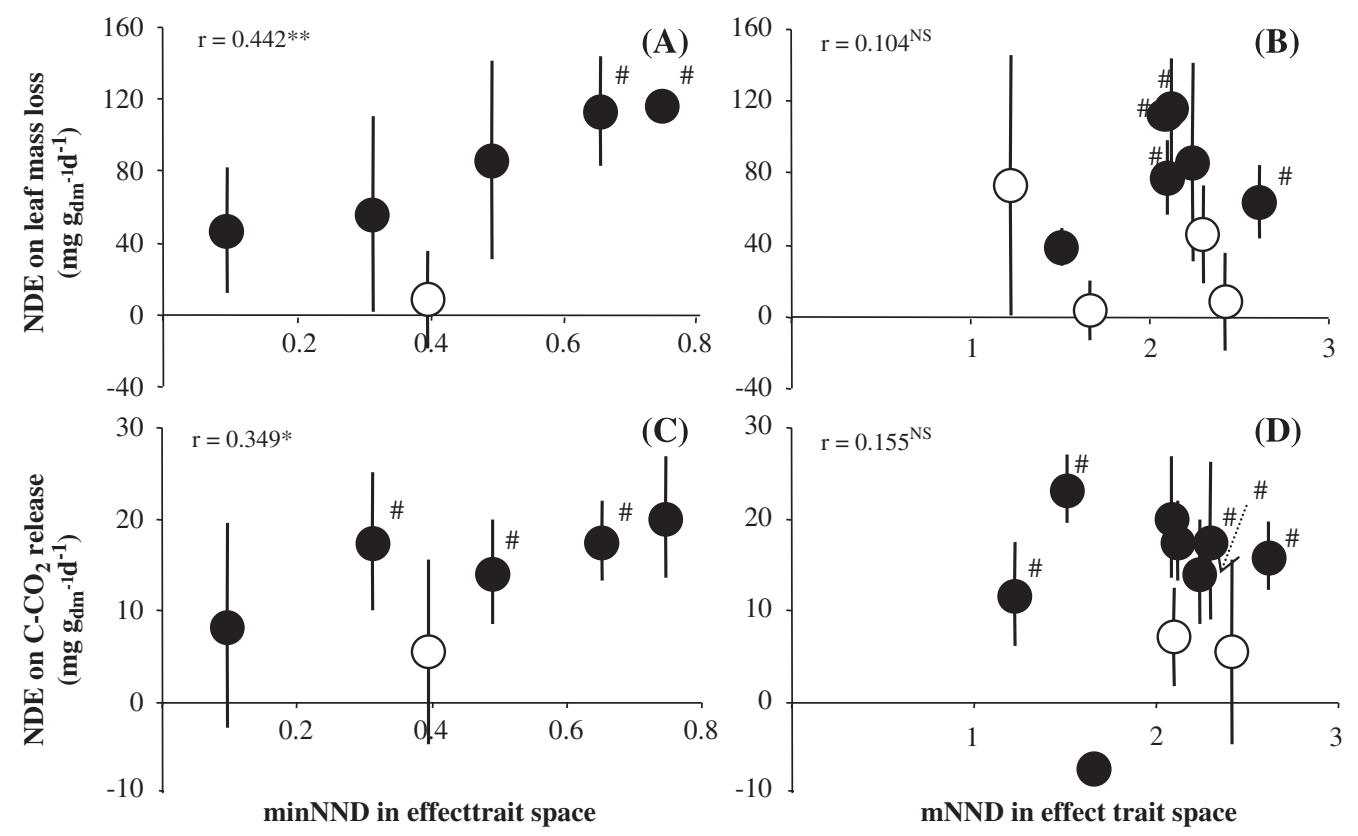

Fig. 3. Net diversity effect of the dissimilarity (minNND and $\mathrm{mNND}$ ) of faeces characteristics on leaf mass loss and $\mathrm{C}-\mathrm{CO} \mathrm{O}_{2}$ release. Correlation coefficients are given in each panel. Symbols are interpreted as in Fig. $2{ }^{\text {NS }}$ non significant; ${ }^{* *} p<0.01 ;{ }^{*} p<0.05$. 

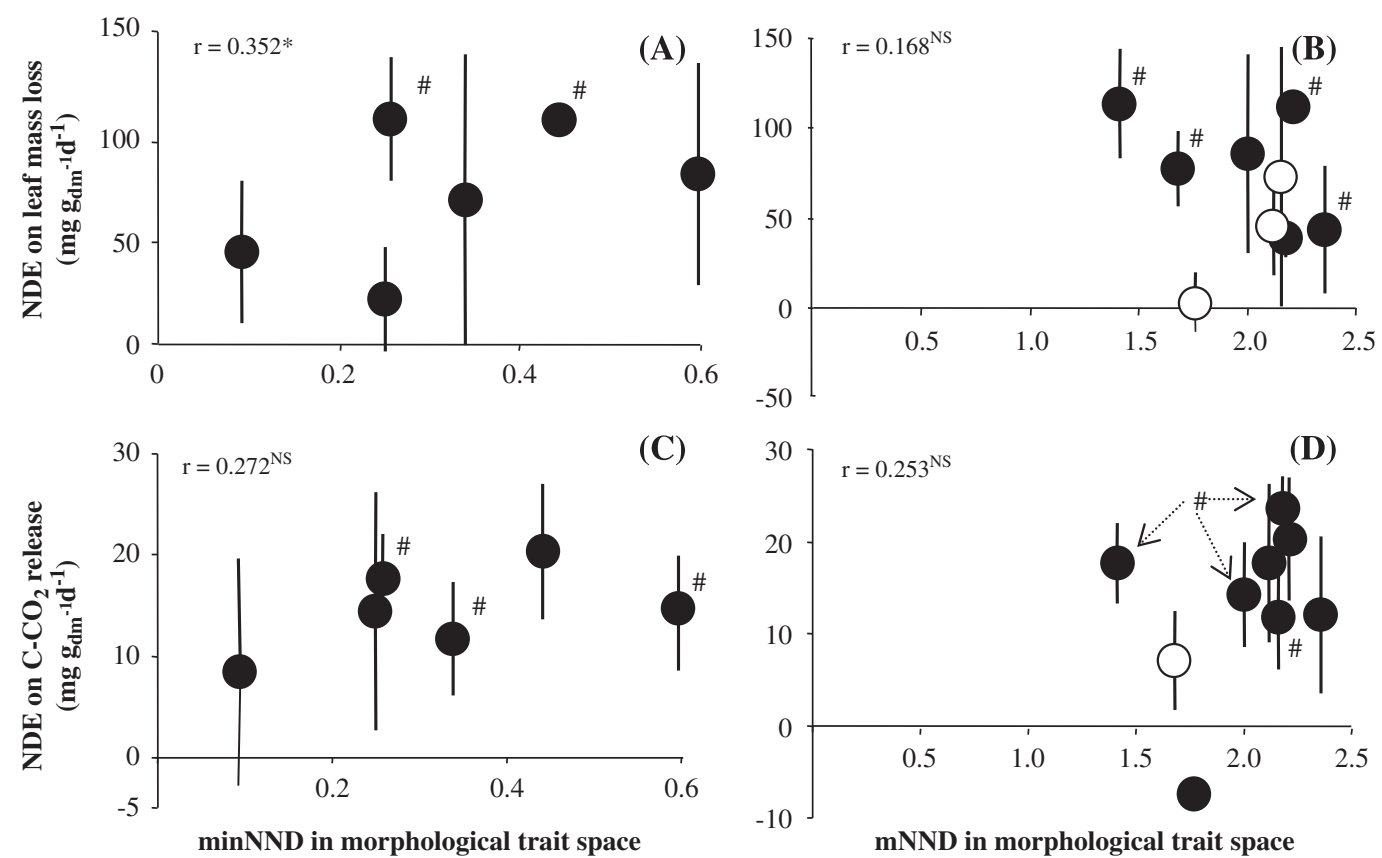

Fig. 4. Net diversity effect of morphological trait dissimilarity (minNND and mNND) on leaf mass loss and $\mathrm{C}-\mathrm{CO}_{2}$ release. Correlation coefficients are given in each panel. Symbols are interpreted as in Fig. 2 NS non significant; ${ }^{*} p<0.05$.

authors in a similar context (Coûteaux, Aloui, \& KurzBesson 2002; Zimmer, Kautz, \& Topp 2005). No significant species impact on $\mathrm{C}-\mathrm{CO}_{2}$ release was observed, except in the case of D. rubidus (Hedde et al. 2007b). Weak or neutral impacts of arthropod activity on $\mathrm{C}$ mineralization had already been noted in a few studies (Van Wemsen, Verhoef, \& Van Straalen 1993) although contrasting trends had frequently been reported (Hattenschwiler \& Bretscher 2001). Maraun and Scheu (1996) suggested that these conflicting results are presumably caused by investigating different litter types for different time periods.

One important result of our work was that the minimum nearest-neighbour distance in the effect and morphological trait spaces influenced assemblage effects on leaf degradation. This confirms that trait-based approaches are meaningful when studying the relationships between biological diversity and environmental processes regarding soil macro-invertebrates, as has already been documented in plants (Loreau 2000b; Franzén 2004; Thein, Roscher, \& Schulze 2008). Furthermore, the minimum nearest-neighbour distances obtained with both classes of traits strongly correlated with each other. This validates the chosen set of morphological traits as a mirror of the functional abilities of different species to degrade leaf litter. This therefore agrees with the idea that functional equivalence (or redundancy), if existing, is more likely to occur between closely related, morphologically similar species that use similar resources in a similar way (Petchey \& Gaston 2002; Loreau 2004; Mouillot, Dumay, \& Tomasini 2007).

Another striking result was that the effects of the macro-invertebrate assemblage on leaf mass loss and, to a lesser extent, on $\mathrm{C}$ mineralization, were closely related to the minimum nearest-neighbour distance in the effect and morphological trait spaces, whereas no pattern developed using mean distances. This suggests that the processes reached their highest rates when the two closest species in the assemblage trait space presented limited functional or morphological similarities, while the mean similarity between all species was of no importance. This agrees with the conclusions reached when testing diversity-productivity relationships using plant functional types (Diaz \& Cabido 2001; Engelhardt 2006).

To date, only a few studies have addressed the functional dimension of soil fauna diversity (Heemsbergen et al. 2004) and most of them have focused on the impact of mesofauna species richness on boreal humus. They provided little evidence of any significant effects on either soil processes or plant growth (Setälä, Laasko, Mikola, \& Huhta 1998; Setälä 2002). Rather, processing of this humus type appeared to be driven by the activity of key species (Huhta et al. 1998). Heemsbergen et al. (2004) studied species assemblages comprising different feeding guilds (i.e. geophagous and geo-saprophagous earthworms, saprophagous arthropods) and found a 
positive relationship between soil processes (respiration and leaf mass loss) and a measure of functional dissimilarity based on the per capita effects of selected species. Although the present study only considered a single feeding group of invertebrates, it produced similar results, thus reinforcing the relevance of functional dissimilarity approaches for soil invertebrate biodiversity-function experiments.

Transgressive overyielding was found in $40 \%$ and $50 \%$ of the results concerning leaf mass loss and $\mathrm{C}$ mineralization, respectively. This indicates that, to a great extent, species complementarity may explain assemblage effects on processes by modulating either resource partitioning (also named niche complementarity) or facilitative interaction (Loreau \& Hector 2001a). For instance, in the present study, resource partitioning could occur if species did not feed on precisely the same parts of the dead leaves. As an example, we observed that $C$. latestriatus tended to feed on leaves by making holes inside them, and was thus comparable to pitfeeding phytophagous insects. Conversely, all other species fed on the leaf edges. Species complementarity may also result from facilitation, insofar as the effect of a given species may alter litter material in such a way that it became more readily usable by others (Gobat, Aragno, \& Matthey 1998). Very little information is available at present on direct facilitative interactions between soil macrofauna species, but the indirect impacts of macro-invertebrates on microbial communities have been extensively described (Brown 1995; Cárcamo et al. 2000; Scheu, Schlitt, Tuinov, Newington, \& Helfin 2002). During the present study, neutral interactions were also detected in $40 \%$ and $20 \%$ of the results of leaf mass loss and $\mathrm{C}$ mineralization, respectively, whereas selection effects occurred in fewer than $20 \%$ of assemblages for both processes. C. latestriatus was present in most assemblages where a selection effect on leaf mass loss was detected; this species performed best during single-species experiments. Negative interactions were only recorded in the 4-species assemblage, supporting the lack of evidence for competitive exclusion in soil communities suggested by Wardle (2006).

Our findings support the idea that species richness is of importance to ecosystem function, but only to the extent that it provides functional variation related to the particular function considered (Loreau 2000b). We showed that for a given number of species, different assemblages varied in their effects on leaf degradation. Transgressive overyielding was only found in twospecies systems. Although the richness gradient studied in our work was mainly restricted to small species numbers, our results support the idea that process saturation can occur with a very small number of species as it has already been demonstrated (Liiri, Setälä, Haimi, Pennanen, \& Fritze 2002; Heemsbergen et al. 2004). For instance, considerable functional redundancy has been found in fungal (Setälä \& McLean 2004), microarthropod (Liiri et al. 2002) and macrofaunal communities (Heemsbergen et al. 2004). This is also consistent with findings from studies on species richness-plant productivity (Hooper 1998; Hector, Beale, Minns, Otway, \& Lawton 2000). On the other hand, no such process saturation was observed when functional or morphological dissimilarities were considered. In the same way, Hooper and Dukes (2004) found a positive linear response of productivity to an increase in plant functional groups, and Heemsbergen et al. (2004) described a linear response of leaf degradation to an increase in species functional dissimilarity in soil invertebrate assemblages.

\section{Conclusion}

In order to estimate functional and morphological diversities, dissimilarity indices were computed using a 'trait space' approach (Heemsbergen et al. 2004). When compared with an a priori classification (Diaz \& Cabido 2001) this approach enabled detection of most of the functional variation responsible for diversity effects (Petchey \& Gaston 2002; Heemsbergen et al. 2004; Mouillot et al. 2005; Wright et al. 2006). This underlines that accurate functional or morphological traits can be used successfully to explore relationships between soil function and diversity. Future studies on soil biodiversity-function relationships should thus aim to identify relevant sets of traits to enable the accurate quantification of functional diversity in an assemblage. Such an approach in natural ecosystems represents a challenging way to investigate how community assembly rules may affect critical soil processes.

Finally, in the case of detritivorous soil invertebrates, species fitness traits linked to feeding activities (resource foraging, digestion, etc.) are associated with the role of species on soil processes such as organic matter dynamics or aggregation. However, the niche limitation/limiting similarity theory predicts that in a given community, species that share similar traits involved in their fitness will have access to fewer resources because of interspecific competition (MacArthur and Levins 1967). An interesting hypothesis therefore needs to be tested; i.e. process rates (e.g. OM dynamics) can be explained by the niche limitation theory (interspecific interactions) that drives species access to resources (decaying organic matter).

\section{Acknowledgments}

Financial support for this work was provided by a grant from the Conseil Régional of Haute-Normandie 
to $\mathrm{MH}$ through the SCALE PPF. The authors are grateful to Philippe Delporte (ECODIV) for his technical support concerning microcosm experiments and to Pierre Margerie (ECODIV) for helpful comments on early versions of the manuscript. Many thanks to the three anonymous referees and Klaus Hövemeyer for their insights and criticisms.

\section{Appendix A. Supplementary material}

The online version of this article contains additional supplementary data. Please visit doi:10.1016/j.baae. 2009.10.009.

\section{References}

Anderson, J. M. (1975). The enigma of soil animal species diversity. In J. Vanek (Ed.), Progress in soil zoology (pp. 5158). Prague: Academia.

Aubert, M., Hedde, M., Decaëns, T., Bureau, F., Margerie, P., \& Alard, D. (2003). Effects of tree canopy on earthworms and other macro-invertebrates in beech forests of Upper Normandy (France). Pedobiologia, 47.

Brown, G. (1995). How do earthworms affect microfloral and faunal community diversity? Plant and Soil, 209-231.

Cárcamo, H. A., Abe, T. A., Prescott, C. E., Holl, F. B., \& Chanway, C. P. (2000). Influence of millipedes on litter decomposition, $\mathrm{N}$ mineralization, and microbial communities in a coastal forest in British Columbia, Canada. Canadian Journal of Forest Research, 30, 817-826.

Coûteaux, M.-M., Aloui, A., \& Kurz-Besson, C. (2002). Pinus halepensis litter decomposition in laboratory microcosms as influenced by temperature and a millipede, Glomeris marginata. Applied Soil Ecology, 20, 85-96.

Diaz, S., \& Cabido, M. (2001). Vive la difference: Plant functional diversity matters to ecosystem processes. Trends in Ecology and Evolution, 16, 646-655.

Díaz, S., Hodgson, J. G., Thompson, K., Cabido, M., Cornelissen, J. H. C., Jalili, A. et al. (2004). The plant traits that drive ecosystems: Evidence from three continents. Journal of Vegetation Science, 15, 295-304.

Engelhardt, K. A. M. (2006). Relating effect and response traits in submersed aquatic macrophytes. Ecological Applications, 16, 1808-1820.

Franzén, D. (2004). Plant species coexistence and dispersion of seed traits in a grassland. Ecography, 27, 218-224.

Gobat, J.M., Aragno, M., \& Matthey, W. (1998). Le sol vivant: Base de pédologie, biologie des sols. Presse Polytechnique et Universitaire Romande.

Hattenschwiler, S., \& Bretscher, D. (2001). Isopod effects on decomposition of litter produced under elevated $\mathrm{CO}_{2}, \mathrm{~N}$ deposition and different soil types. Global Change Biology, 7, 565-579.

Hector, A., Beale, A., Minns, A., Otway, S., \& Lawton, J. H. (2000). Consequences of loss of plant diversity for litter decomposition: Mechanisms of litter quality and microenvironment. Oikos, 90, 357-371.
Hedde, M., Aubert, M., Bureau, F., Margerie, P., \& Decaëns, T. (2007a). Soil detritivore macro-invertebrate assemblages throughout a managed beech rotation. Annals of Forest Science.

Hedde, M., Bureau, F., Akpa-Vinceslas, M., Aubert, M., \& Decaëns, T. (2007b). Beech leaf degradation in laboratory experiments: Effects of eight detritivorous invertebrate species. Applied Soil Ecology, 35, 291-301.

Heemsbergen, D. A., Berg, M. P., Loreau, M., van Hal, J. R., Faber, J. H., \& Verhoef, H. A. (2004). Biodiversity effects on soil processes explained by interspecific functional dissimilarity. Science, 306, 1019-1020.

Hooper, D. U. (1998). The role of complementarity and competition in ecosystem responses to variation in plant diversity. Ecology, 79, 704-719.

Hooper, D. U., Chapin, F. S., Ewel, J. J., Hector, A., Inchausti, P., Lavorel, S. et al. (2005). Effects of biodiversity on ecosystem functioning: A consensus of current knowledge. Ecological Monographs, 75, 3-35.

Hooper, D. U., \& Dukes, J. S. (2004). Overyielding among plant functional groups in a long-term experiment. Ecology Letters, 7, 95-105.

Huhta, V., Persson, T., \& Setälä, H. (1998). Functional implications of soil fauna diversity in boreal forests. Applied Soil Ecology, 10, 277-288.

Lavelle, P., Decaëns, T., Aubert, M., Barot, S., Blouin, M., Bureau, F. et al. (2006). Soil invertebrates and ecosystem services. European Journal of Soil Biology, 42, S3-S15.

Lavelle, P., \& Spain, A. V. (2001). Soil ecology. Dordrecht: Kluwer Academic Publishers.

Lavorel, S., \& Garnier, E. (2001). Aardvarck to Zyzyxiafunctional groups across kingdoms. New Phytologist, 149, 360-363.

Liiri, M., Setälä, H., Haimi, J., Pennanen, T., \& Fritze, H. (2002). Relationship between soil microarthropod species diversity and plant growth does not change when the system is disturbed. Oikos, 96, 137-149.

Loreau, M. (1998). Biodiversity and ecosystem functioning: A mechanistic model. Proceedings of the National Academy of Science USA, 95, 5632-5636.

Loreau, M. (2000a). Are communities saturated? On the relationship between $\alpha, \beta$ and $\gamma$ diversity. Ecology Letters, 3, 73-76.

Loreau, M. (2000b). Biodiversity and ecosystem functioning: Recent theoretical advances. Oikos, 91, 3-17.

Loreau, M., \& Hector, A. (2001a). Partitioning selection and complementarity in biodiversity experiments. Nature, 412 \& 413, 72-76 \& 548 .

Loreau, M., Naeem, S., Inchausti, P., Bengtsson, J., Grime, J. P., Hector, A. et al. (2001b). Biodiversity and ecosystem functioning: Current knowledge and future challenges. Science, 294, 804-808.

Loreau, M. M. (2004). Does functional redundancy exist? Oikos, 104, 606-611.

MacArthur, R. H., \& Levins, R. (1967). The limiting similarity, convergence, and divergence of coexisting species. American Naturalist, 101, 377-385.

Maraun, M., \& Scheu, S. (1996). Changes in microbial biomass, respiration and nutrient status of beech (Fagus 
sylvatica) leaf litter processed by millipedes (Glomeris marginata). Oecologia, 107, 131-140.

Mouillot, D., Dumay, O., \& Tomasini, J. A. (2007). Limiting similarity, niche filtering and functional diversity in coastal lagoon fish communities. Estuarine, Coastal and Shelf Science, 71, 443-456.

Mouillot, D., Stubbs, W., Faure, M., Dumay, O., Tomasini, J., Wilson, J. et al. (2005). Niche overlap estimates based on quantitative functional traits: A new family of nonparametric indices. Oecologia, 145, 345-353.

Naeem, S., \& Wright, J. P. (2003). Disentangling biodiversity effects on ecosystem functioning: Deriving solutions to a seemingly insurmountable problem. Ecology Letters, 6, 567-579.

Petchey, O. L., \& Gaston, K. J. (2002). Functional diversity (FD), species richness and community composition. Ecology Letters, 5, 402-411.

Polley, W. H., Wilsey, B. J., \& Tischler, C. R. (2007). Species abundances influence the net biodiversity effect in mixtures of two plant species. Basic and Applied Ecology, 8, 209-218.

Pywell, R. F., Bullock, J. M., Roy, D. B., Warman, L., Walker, K. J., \& Rothery, P. (2003). Plant traits as predictors of performance in ecological restoration. Journal of Applied Ecology, 40, 65-77.

R Development Core Team, P. (2004). R: A language and environment for statistical computing. Vienna, Austria: $\mathrm{R}$ Foundation for Statistical Computing.

Rosenfeld, J. S. (2002). Functional redundancy in ecology and conservation. Oikos, 98, 156-162.

Scheu, S., Schlitt, N., Tuinov, A. V., Newington, J. E., \& Helfin, J. T. (2002). Effects of the presence and community composition of earthworms on microbial community functioning. Oecologia, 133, 254-260.

Setälä, H. (2002). Sensitivity of ecosystem functioning to changes in trophic structure, functional group composition and species diversity in belowground food webs. Ecological Research, 17, 207-215.
Setälä, H., Laasko, J., Mikola, J., \& Huhta, V. (1998). Functional diversity of decomposer organisms in relation to primary production. Applied Soil Ecology, 9, 25-31.

Setälä, H., \& McLean, M. A. (2004). Decomposition rate of organic substrates in relation to the species diversity of soil saprophytic fungi. Oecologia, 139, 98-107.

Stubbs, W. J., \& Bastow Wilson, J. (2004). Evidence for limiting similarity in a sand dune community. Journal of Ecology, 92, 557-567.

Tenenhaus, M., \& Young, F. W. (1985). An analysis and synthesis of multiple correspondence analysis, optimal scaling, dual scaling, homogeneity analysis and other methods for quantifying categorical multivariate data. Psychometrika, 50, 91-119.

Thein, S., Roscher, C., \& Schulze, E.-D. (2008). Effects of trait plasticity on aboveground biomass production depend on species identity in experimental grasslands. Basic and Applied Ecology, 9, 475-484.

Van Wemsen, J., Verhoef, H. A., \& Van Straalen, N. M. (1993). Litter degradation stage as a prime factor for isopod interaction with mineralization process. Soil Biology and Biochemistry, 25, 1175-1183.

Violle, C., Navas, M.-L., Vile, D., Kazakou, E. C. F., Hummel, I., \& Garnier, E. (2007). Let the concept of trait be functional. Oikos, 116, 882-892.

Wardle, D. A. (2006). The influence of biotic interactions on soil biodiversity. Ecology Letters, 9, 870-886.

Weiher, E., Clarke, G. D. P., \& Keddy, P. A. (1998). Community assembly rules, morphological dispersion and the co-existence of plant species. Oikos, 81, 309-322.

Wright, J. P., Naeem, S., Hector, A., Lehman, C., Reich, P. B., Schmid, B. et al. (2006). Conventional functional classification schemes underestimate the relationship with ecosystem functioning. Ecology Letters, 9, 111-120.

Zimmer, M., Kautz, G., \& Topp, W. (2005). Do woodlice and earthworms interact synergistically in leaf litter decomposition? Functional Ecology, 19, 7-16. 